\begin{tabular}{|c|c|c|}
\hline $\begin{array}{l}\text { PKS } \\
\text { PUBLIC } \\
\text { KNOWLEDGE } \\
\text { PROJECT }\end{array}$ & $\begin{array}{c}\text { Revista de GEOGRAFIA } \\
\text { (RECIFE) } \\
\text { http://www.revista.uffe.br/revistageografia }\end{array}$ & $\begin{array}{l}\text { OJS } \\
\frac{\text { OPEN }}{\text { JOURAL }} \\
\text { SYSTEMS }\end{array}$ \\
\hline
\end{tabular}

\title{
AS PAISAGENS DO MEDO DAS ARMAS NUCLEARES NA CULTURA MIDIÁTICA ESTADUNIDENSE E JAPONESA
}

\author{
Mario Marcello Neto ${ }^{1}$ \\ ${ }^{1}$ Doutorando em História na UFRGS.Email: mariomarceloneto@yahoo.com.br \\ Artigo recebido em 25/08/2017 e aceito em 01/10/2017

\begin{abstract}
RESUMO
O medo é algo volátil, inesperado, invisível e as suas reações a ele são da mais pura subjetividade possível. No entanto, o medo não deixa de ser algo que pode ser controlado, construído e manipulado. Este trabalho pretende discutir como as paisagens do medo (TUAN, 2005) são construídas pela cultura da mídia (KELLNER,2001) estadunidense e japonesa, no que diz respeito as armas nucleares. Essas paisagens do medo das armas nucleares são objeto de estudo neste artigo, uma vez que estas desvelam algo peculiar que o medo das armas nucleares gera nas populações humanas, que se divide no dilema entre: a extinção da humanidade e o perigo da radiação. A partir de um estudo pormenorizado do mangá "Gen - pés-descalços" de Keiji Nakazawa (sobrevivente da bomba atômica de Hiroshima) é possível traçar uma reflexão a respeito da construção de topofobias e topocídios a partir de elementos paisagísticos que não se diferem tanto de uma paisagem de guerra, mas se constituem essencialmente diferentes como lugares a partir da presença da radiação ou do medo da extinção de suas vidas pelas armas nucleares.
\end{abstract}

Palavras-chaves: Medo. Paisagens do Medo. Topocídio. Cultura da Mídia.

\section{THE LANDSCAPES OF THE FEAR OF NUCLEAR WEAPONS IN THE AMERICAN AND JAPANESE MEDIA CULTURE}

\begin{abstract}
Fear is something volatile, unexpected, invisible and your reactions to it are of the purest subjectivity. However, fear is something that can be controlled, constructed and manipulated. This paper intends to discuss how the landscapes of fear (TUAN, 2005) are constructed by the media culture (KELLNER, 2001) in the United States and Japan, with regard to nuclear weapons. These landscapes of fear of nuclear weapons are the subject of study in this paper, since they reveal something peculiar that the fear of nuclear weapons generates in the human populations, that is divided in the dilemma between: the extinction of the humanity and the danger of the radiation. From a detailed study of the "Barefoot Gen" manga by Keiji Nakazawa (survivor of the Hiroshima atomic bomb) it is possible to draw a reflection on the construction of topphobias and topocídios from landscaping elements that do not differ so much from a landscape of war, but are essentially different as places from the presence of radiation or fear of the extinction of their lives by nuclear weapons.
\end{abstract}

Keywords: Fear, Landscapes of Fear, Topocide, Media Culture. 


\section{CONSIDERAÇÕES INICIAIS}

A constituição social do medo é algo que gera debates e tentativas constantes de aprofundamentos e estudos. No entanto, algo que fica evidente é que o ser humano é notavelmente marcado pelo medo em sua forma de manifestação social. Segundo Skoll (2010), o medo permite estabelecer noções de perigo, limites mentais e físicos bem como justifica e estabelece hierarquias e regras. O medo é sempre algo gerado em virtude de algum evento, como afirma Koonings e Kruijt (1999), desta forma ele pode ser algo que acontece por causas naturais ou provocado conscientemente. A coerção é uma das formas mais comuns de manifestação do medo como forma de legitimação da ordem vigente.

Neste trabalho, proponho uma análise da construção das paisagens do medo (TUAN, 2005) com relação a bomba atômica e seu artefato originário: a arma nuclear. Para isso, é preciso uma imersão sobre o que significa paisagens de medo, como são construídas e quais as peculiaridades que estas paisagens apresentam com relação a bomba atômica. A construção imagética de uma destruição por meio das armas nucleares no imaginário cinematográfico e da cultura midiática é, muitas vezes, extremamente afastada dos registros e relatos do único evento atômico ocorrido no Planeta Terra, nas cidades de Hiroshima e Nagasaki em 1945.

Compreender que a destruição causada pelo artefato nuclear é algo importante, mas não determinante para construção desta paisagem é um primeiro passo. No entanto, é preciso compreender, também, como se dá a relação entre a destruição momentânea e a degeneração dos corpos e o medo causado pela invisibilidade dos efeitos radioativos herdados de uma arma nuclear. Esse diferencial da (sensação de) eternidade da radioatividade é muito importante de ser destacado.

Para que este estudo ocorra de maneira mais sistematizada utilizaremos como objetos de estudo o anime "Gen Pés-descalços" (dirigido por Tengo Yamada, 1976) e o mangá homônimo que deu origem ao filme, feito por Keiji Nakazawa. Para executar essa análise deterei minha atenção nos elementos imagéticos do filme e do mangá que permitem construir a noção de uma paisagem do medo em constante comparação com elementos midiáticos que realizam uma representação da temática do medo nuclear, juntamente com registros fotográficos e relatos memorias sobre a cidade de Hiroshima após a bomba atômica, realizando assim um contraste entre as paisagens de medo construídas por Nakazawa e as paisagens de medo estabelecidas com relação a um mundo distópico destruído por armas nucleares. Estes dois modelos de construções de paisagens de medo são formas de pensar que 
a construção dessas paisagens independe do correspondente no "mundo real", sendo construída a através do imaginário e da sobreposição de imagens que compõem um modelo paisagístico do medo das armas nucleares que nem sempre se refere diretamente a bomba atômica lançada sob o Japão no final da Segunda Guerra Mundial.

\section{A PAISAGEM DO MEDO NA HIROSHIMA DE NAKAZAWA}

A ideia de paisagem do medo é algo complexo e que exigiria uma grande incursão para ser explicada de forma detalhada neste texto. No entanto, farei aqui uma breve discussão teórica do arcabouço que necessito para construção de uma matriz de pensamento que permita estruturar a ideia de uma paisagem do medo.

Partindo das noções de Tuan (1983), é impossível dissociar paisagem e lugar. Estes dois conceitos estão imbricados no sentido de que a paisagem, para o autor supracitado, pode ser um retrato natural de tudo o que se percebe no espaço, como uma construção imagética influenciada e vivida de diversas formas por diversas questões (sentimentos, afetos, rejeições) que fazem desta paisagem um lugar ou um não lugar. A noção afetiva atribuída a paisagem é que determina o lugar, na visão de Tuan (1983).

Desta forma, falar de paisagem é sobretudo falar de lugar. O lugar subjetivado, a partir de uma noção afetiva (de repulsa ou atração) é constituído de paisagens, de visões do espaço vivido que permitem essa construção sociocultural, num contexto de constantes disputas entre legitimações de poder e pautas políticas acirradas, o lugar e a paisagem ocupam um lugar central na forma pela qual o interesse olha para o espaço (urbano ou rural), buscando a partir deste olhar negligenciar problemas e/ou solucionar outros.

Isso fica evidente quando se mapeia paisagens do medo em áreas urbanas das grandes capitais brasileira. Para determinados segmentos políticos conservadores, essas paisagens do medo estarão restritas apenas a área suburbana e/ou de circulação de pessoas mais pobres. No entanto, se for avaliado por uma visão política mais progressista essa mesma paisagem apontada como um lugar de medo não o é percebida, por muitos de seus moradores. Isso não se trata de uma visão estar certa ou errado, mas sim que a construção dessas imagens e destes conceitos estão, sempre, imbuídas em diversos elementos de forte cunho ideológico.

A paisagem do medo, de forma conceitual, se constitui, para Tuan (2005), de uma paisagem subjetivada, na qual torna-se um lugar, que se demonstra aversão, repulsa e, acima de tudo, medo! Esse medo modifica as formas de se relacionar com aquele espaço, coloca em 
conflito os interesses políticos e as pautas de discussão sobre o uso daquele espaço. O medo, nestes casos, torna-se parte integrante de um discurso organizador e moralizador do espaço vivido. Sendo ele um dos principais responsáveis por organizar e sistematizar as formas vivenciar o espaço.

Estes sentimentos de pertença a um determinado lugar, o que Tuan (2005) chamou de Topofilia, são essenciais para a desconstrução dessas paisagens do medo. A topofilia é sobretudo subjetiva, mas permite também gerar sentimentos coletivos de pertença e afeto aos lugares existentes. Essa forma de ver e perceber o espaço vivido dão contornos muito diferentes ao caótico mundo em que o medo impera nas relações sociais.

O seu inverso, a Topofobia, é a aversão aos lugares, aos topos. Um sentimento de repulsa, medo que leva a uma relação caótico com os lugares. Muitas vezes essa relação é tão complexa e tensa que leva a um topocídio, ou seja, uma morte desses lugares, tornando-se lugares fantasmas, abandonados e desvalorizados por todos em sua volta.

Quando se trata de paisagens de guerra, de maneira geral, no censo comum, remete-se a ideia de destruição, sangue e mortos. Essas paisagens, sejam contemporâneas ou passadas, são sempre marcadas por uma ideia de destruição material e pessoal. Um sentimento claro de perda. Porém, não é necessariamente de medo. A guerra nem sempre foi vista como um período de medo. Isso se dá, segundo Keegan (2006), devido a uma série de fatores, entre eles a valorização da guerra quanto um evento justo, necessário, o discurso da inevitabilidade da guerra e os esforços constantes de determinados países e contextos para que a guerra aconteça ou não acabe.

Essa relação entre destruição e as paisagens de guerra ficam explícitas em guias facilmente encontrado em lojas online de compra de livros, na qual o título "Landscape of War", tradução literal para o inglês de "paisagens da guerra", criam cenários que possam ser reproduzidos em maquetes e dioramas, sempre evocando uma noção de contexto histórico, tecnologia bélica e paisagística envolvidas numa lógica de destruição.

Se guerra e destruição são sinônimos, o dia 6 de agosto de 1945 criou um paradigma diferenciado na construção dessas paisagens de guerra. Esse paradigma está presente a partir da construção da paisagem de Hiroshima, cidade japonesa, afetada pela primeira arma atômica lançada sobre uma população humana. A destruição causada pela bomba atômica foi, e ainda é, imensamente maior que qualquer outra bomba já produziu. Porém, as descrições paisagísticas que se fez do evento não diferem tanto de uma lógica da guerra: destruição de prédios, mortos, fogo, devastação ambiental. 
O que se modifica radicalmente com a questão atômica não está apenas na proporção do que foi afetado. Não é o número absurdo de mortos (estimados em 200 mil pessoas em Hiroshima), nem a destruição quase total de tudo que estava construído no epicentro da bomba. O que fundamentalmente sustentou a construção paisagística da bomba atômica são os efeitos que a radiação deixou em curto, médio e longo prazo. Muito mais do que qualquer discussão sobre a destruição, a problemática agora são as deformações causadas pela radiação, algo estimado apenas em ficção científica que se torna realidade da forma mais cruel e abusiva possível.

A construção da paisagem do medo das armas nucleares é o objetivo central de compreensão deste trabalho. Como Tuan (2005) afirma, o medo é algo comum a todos os seres superiores, principalmente no que diz respeito aos seres humanos. Todo medo é causado por algum fator que envolve uma construção social. Seja um ato de intimidação, um ataque de algum animal feroz, algo que é eminente as relações sociais. No entanto, o medo das armas nucleares é um medo que envolve diretamente outras dimensões. Como afirma Gunther Anders (2011), o perigo eminente que as armas nucleares deixam como legado é possível (e provável) extinção da humanidade por meios próprios da humanidade.

O ser humano passa a ter o controle não só de países e populações, mas também pode decidir quando se acaba ou não a vida na Terra, uma vez que possui tecnologia destrutiva suficiente para isso. Além disso, seguindo esta linha de pensamento, as armas nucleares imbricam em questões claras que não dizem respeito ao medo do que aconteceu, mas principalmente de um medo do devir, do que pode acontecer com o ser humano.

Esse medo do devir se deve a dois fatores, segundo Stearns (2008): 1) o fato de o ataque nuclear ao Japão ser considerado justificável por se tratar de um país imperialista pertencente ao Eixo durante a Segunda Guerra Mundial; 2) os danos causados pela radiação preocupam muito mais a humanidade do que a destruição causada. As cenas de horror, o desconhecimento e a impossibilidade de mensurar suas consequências, bem como a construção imagética de um cenário catastrófico com pessoas sem peles, com o corpo parcialmente derretido agonizando, perdendo os cabelos ao longo dos dias, com vômitos compulsivos forma efetivando uma memória coletiva sobre a bomba atômica, como afirma Zwigenberg (2014) que conforme eram divulgados novos dados sobre os danos de uma arma nuclear (vistos, sempre, pelos EUA, como um grande avanço da ciência bélica), mais se aguçava a mente humana no sentido de se temer (medo) um armamento que se diz necessário existir, mas que pode oferecer os piores cenários com relação a humanidade no futuro. 
Os tensos e cambiantes contextos que se seguiram a bomba atômica, com a Guerra Fria e os constantes conflitos indiretos entre os dois blocos (capitalista e socialista) - como a Guerra da Coréia, Crise dos Mísseis em Cuba, Guerra do Vietnã e Guerra do Afeganistão na década de 1980 - proporcionaram a criação de uma conjuntura de que uma guerra nuclear estivesse sempre em constante possibilidade. Alguns eventos se tornam catalizadores desse medo, que por um motivo consciente ou não é refletido na produção de material audiovisual sobre esta temática. Os eventos que pode-se destacar são: Guerra da Coréia (1950-1954), Crise dos Mísseis (1962), Movimento anti-guerra do Vietnã/ contracultura (1968), Segunda Guerra Fria (1980-1990) e o atentando de 11 de setembro de 2001. O que todos esses eventos têm em comum é o uso do discurso do perigo de uma guerra nuclear. Em virtude do acirramento político e bélico entre diferentes visões de mundo, sejam elas capitalistas e socialistas, sejam ocidentais e orientais entre outras, todas colocavam em pauta o medo das armas nucleares e o perigo que essas traziam para a existência da humanidade. O gráfico abaixo apresenta essa relação dividida pelos períodos supracitados. Vejam como se configuram os picos de medo nessas situações.

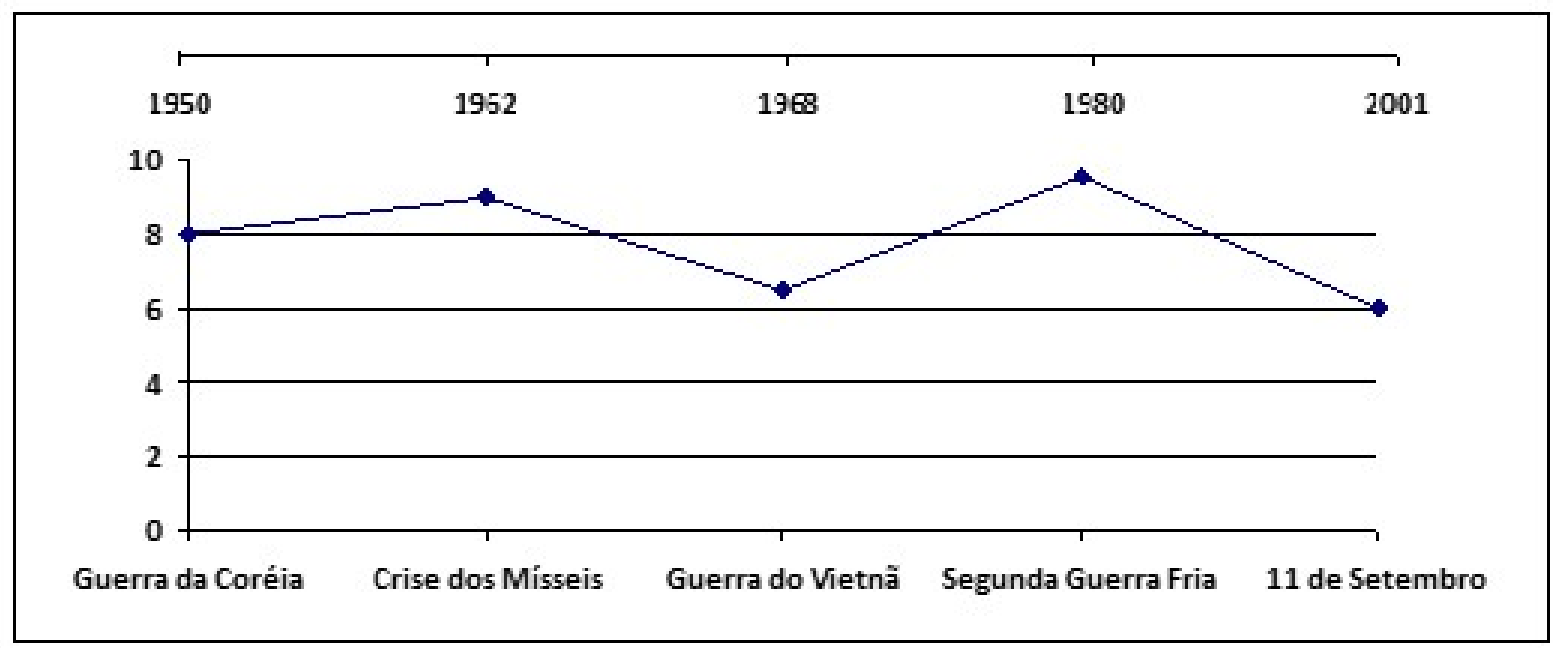

Gráfico 1: Picos de Medo das armas nucleares (1950-2001)

Fonte: Produção própria

É perceptível que o medo das armas nucleares se configura de foram não linear, mas que determinados eventos, sobretudo aqueles que mais repercutem na mídia, e que se alicerçam no medo das armas nucleares, geram paranoias e sensações de medo que colocam a existência da humanidade em risco. É obvio que nem todas as pessoas percebem este medo, nem partilham dele seu código, no entanto, uma boa parcela da sociedade é mobilizada a 
partir dele. Sendo, desta forma o medo o grande responsável por cooptar pessoas em prol de um discurso, como mobiliza-las a resistir a ele (como no caso das manifestações de contracultura no final da década de 1960). Esse medo pauta justificativas políticas para as mais diversas intenções. Isso, dentro de minha proposição de análise foi o que ocorreu durante toda a metade final do século XX, pautando o discurso do medo das armas nucleares em uma possibilidade clara de extermínio da humanidade pelos "Outros", o inimigo que deve ser destruído.

As armas nucleares com seu uso no Japão, ao contrário do que uma lógica humanitária apontaria, aumentou exponencialmente seu grau de produção, fazendo com que o medo de uma extinção da humanidade torna-se o caso de Hiroshima e Nagasaki sistemáticos exemplos do que isso poderia nos levar. A paisagem do medo das armas nucleares que aqui será analisada foi construída por um sobrevivente da bomba atômica. Keiji Nakazawa ao criar o mangá "Gen Pés-descalços" construiu um universo em que essa paisagem do medo das armas nucleares se torna contrastante a todos os cenários projetados em mídias estadunidenses sobre usos de armas nucleares. Esse conflito entre paisagens hipotéticas tão díspares chama a atenção pois revelam tensões e medos diferentes, com motivações distintas, mas que pensam a mesma questão: a sobrevivência da humanidade.

A mídia, pensando aqui em mídia corporativa pertencente ao mainstream comunicacional, e a forma em que é consumida, assistida e presenciada, constitui aquilo que Kellner (2001) chamou de "cultura da mídia". Esta cultura da mídia quando analisada na perspectiva da Teoria Crítica, ou de uma análise criteriosa sobre seus discursos e interesses envolvidos nos processos representacionais e suas formas de consumo, pode servir de instrumento para uma compreensão de que a sociedade não é hegemônica, nem se estabelece apenas a partir do que as instituições de poderes demandam. Os processos de resistência e denuncia as opressões sempre existem, sejam eles com maior ou menor de intervenção no debate na arena pública.

Neste sentido, o que proponho nesta parte do texto é uma breve análise de uma produção japonesa que se "inconforma" com o discurso oficial sobre o passado recente japonês. Se por um lado a parte do passado japonês que mais chama atenção da mídia são elementos que partem de suas de mitologias, história de samurais, seus discursos sobre honradez e lealdade - algo bem discutível segundo Harootunian (2006). Desta forma, destaco 
o trabalho de uma vida de Keiji Nakazawa, na qual a produção do mangá "Hadashi no Gen", me permite inferir sobre questões complexas da relação entre memória, história e esquecimento, bem como compreender a forma com que expor aquilo que Chakarabarty (2000) chamou de "feridas históricas" permite uma relação diferenciada com o passado.

A estória de Nakazawa (2010) conta a trajetória do garoto Gen, residente em Hiroshima antes, durante e depois da bomba atômica ser lançada sob sua cidade natal. No entanto, esse mangá não pode ser simplesmente classificado. Um dos primeiros motivos é que ele é abertamente autobiográfico, ou, a versão que acredito ser mais pertinente, com traços autobiográficos muito forte. Nakazawa faleceu em 2011 vítima de leucemia causada pela radiação da bomba atômica de Hiroshima a qual foi exposto quando criança, em 1945.

O mangá em questão é fruto da reflexão de Nakazawa a partir de 1966, ano em que sua mãe morreu em decorrência da radiação causada pela bomba atômica. A obra "Gen, pésdescalços", com fortes inspirações autobiográficas foi uma forma de falar sobre aquele passado traumático que tanto afetava a vida de seu autor, tendo o mesmo sido censurado em diversos momentos em tentativas de desenhar sobre este evento, principalmente durante a ocupação estadunidense. A obra foi inicialmente publicada em excertos no jornal, a partir de 1972, e só com o sucesso do mesmo é que Nakazawa amplia a estória, compilando-a em 10 volumes que abordam o período anterior ao lançamento da bomba e todo o processo de restruturação da cidade de Hiroshima. A obra foi finalizada somente em 1985, fazendo uma densa incursão sobre o processo de destruição causada pelo artefato nuclear e a triste e opressora política de reestruturação que o Japão aplicou aos que sobreviviam, e conviviam, com a radiação.

Portanto, o mangá narra diversos elementos sobre o processo que envolve a bomba atômica, indo muito além de uma discussão memorial, mas realizando uma crítica social, uma crítica as posturas de diversos espectros, desde o Japão imperial - da qual seu pai, segundo o autor, era bem crítico e sofreu grande represália por ter essa postura política - até a política nuclear dos EUA e, principalmente, o obscuro período de ocupação do Japão que deixou rastros de censura incalculável. Tal questão é tão forte, que Nakazawa escondeu diversos desenhos que havia feito sobre suas memórias visuais com relação aos sobreviventes da bomba atômica, só podendo e conseguindo publicar o mangá na década de 1970, quando a questão política da ocupação se dissipara e a conformação do passado japonês começava a

\footnotetext{
${ }^{1} \mathrm{O}$ nome listado no texto se refere ao título original em japonês colocado sob o alfabeto ocidental. No entanto o nome e a versão de análise que utilizamos para realizar este texto trata-se da versão traduzida pela Editora Conrad sob o título "Gen - Pés-descalços". 
receber críticas por setores da população que não entendiam a postura complacente do arquipélago asiático para com seus algozes da Segunda Guerra Mundial.

No caso de Gen é evidente que o discurso ficcional foi o caminho encontrado por Nakazawa para falar sobre a bomba atômica sem a necessidade de entrar na seara de “comprovação" do que foi dito. Vale lembrar a célebre frase de Vidal-Naquet (1987), na qual afirma que esconder e apagar as evidencias de um crime são práticas máximas de violência praticadas no século XX. O caso da bomba atômica não foi diferente. Não cabe exigir da ficção a aporia da verdade, mas também não se pode desvalida-la por não ter essa aporia. Caso contrário tudo que os historiadores disserem deverá ser tratado como "verdade"?

Nakazawa como bom ficcionista vai a fundo em elementos que talvez só a ficção poderia ser capaz de narrar. A riqueza de detalhes existentes nas suas representações da forma como o ensino japonês foi reestruturado, a organização política foi feita e o tratamento dado as pessoas que sobreviveram à bomba atômica em Hiroshima e Nagasaki, além dos milhares desabrigados e feridos durante os últimos meses de guerra pelas tropas dos EUA permitem compreender que a bomba atômica não é um processo estanque, que acabou no dia 9 de agosto de 1945 .

Um dos focos centrais da narrativa de Nakazawa é a descrição e construção de paisagens (Figura 1), principalmente aquelas responsáveis pela construção do de elementos que remetem ao medo das armas nucleares: pessoas deformadas, as doenças causadas, a paisagem da destruição radioativa da produção agrícola que gerou um extenso período de fome em Hiroshima. Tudo isso contado dia a dia, de forma detalhada pelo autor. 


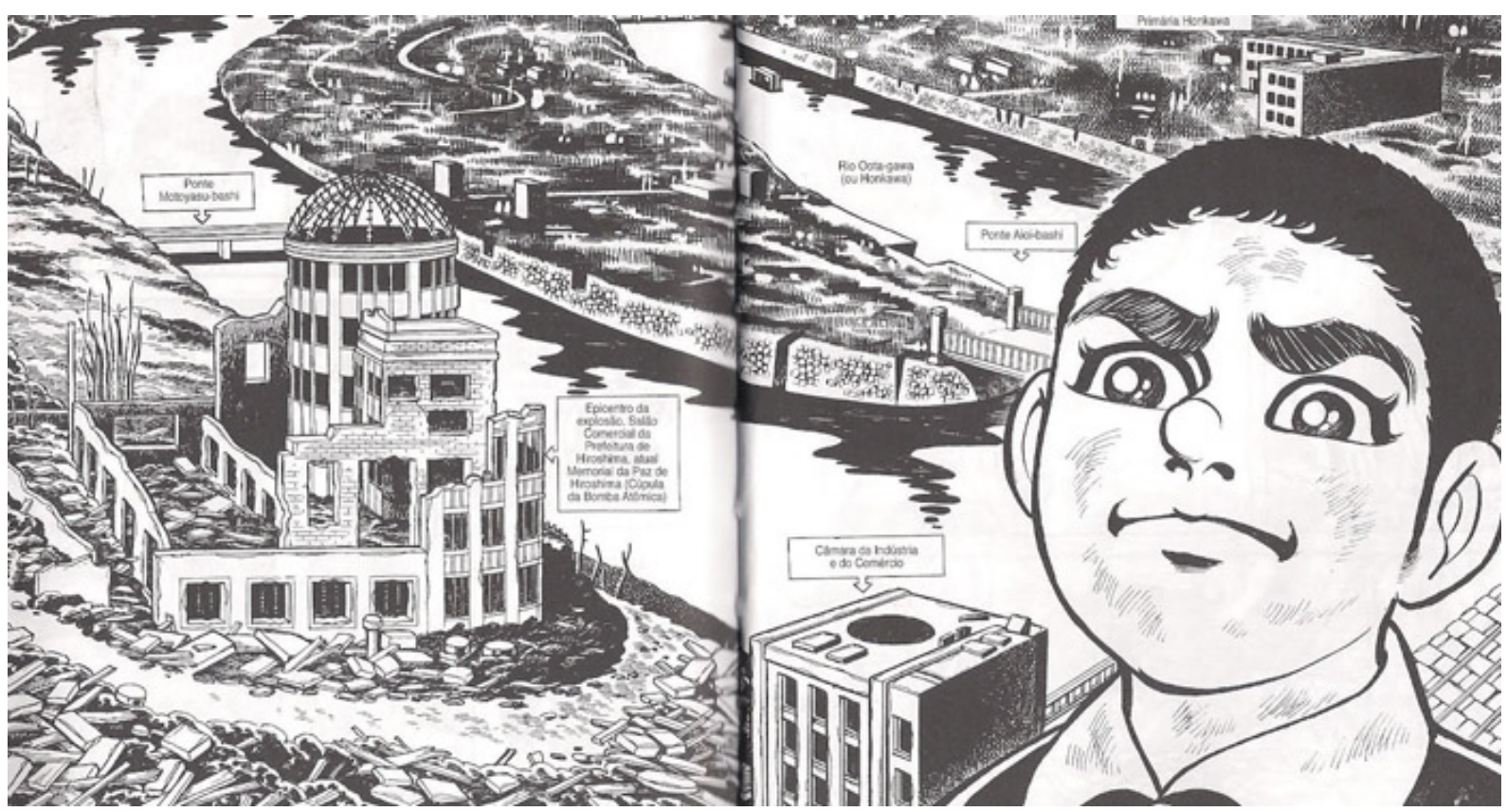

Figura 01: A paisagem do medo na visão de Keiji Nakazawa em Hiroshima após a

bomba atômica. Fonte: NAKAZAWA, 2010, p.15

Essas paisagens e lugares construídos por Nakazawa tem como referente a sua realidade vivida no contexto do pós-bomba atômica. Tal questão fica evidente com os registros fotográficos da época e os diversos relatos existentes sobre o evento. No entanto, no imaginário da cultura da mídia estadunidense o medo das armas nucleares constituiu um arcabouço que envolve desde seres gigantes atômicos, até mundos distópicos completamente destruídos.

É verdade que uma das primeiras aparições de monstros gigantes atômicos se deram no Japão. O famigerado Godzila (figura 2) é o exemplo mais claro disso. Surgido em 1954, segundo Robert Jacobs (2010) o "anfíbio-reptiliano" mais temido do cinema tem sua origem a partir do uso de bomba atômicas que a partir da sua radiação geraram seres mutantes. Esses seres, todos corrompidos no seu desenvolvimento natural pela radiação estão em completo caos biológico, desenvolvendo verdadeiros monstros que assolam a humanidade sobrevivente. 


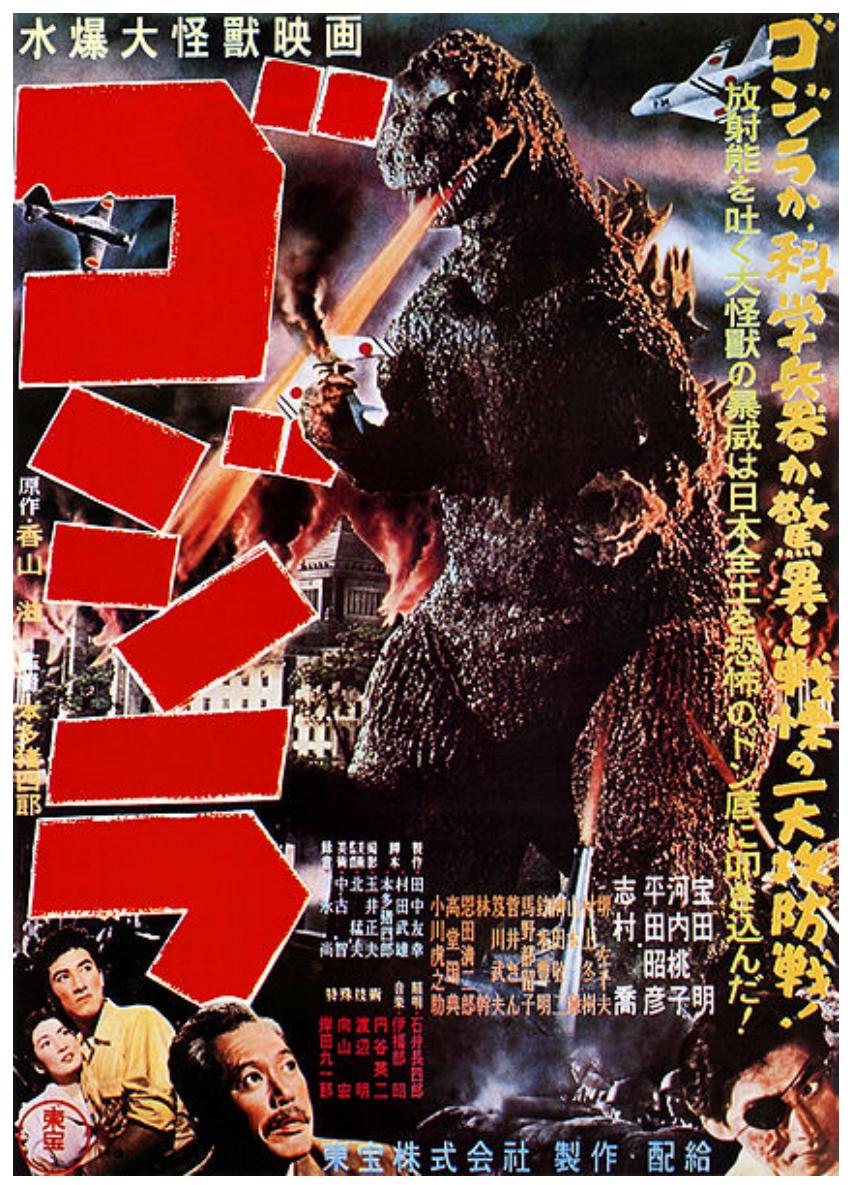

Figura 2: Cartaz japonês do filme "Godzilla" de 1954, com o personagem fruto da radiação em destaque. Fonte: Toho Company Ltd.

No entanto, é nos Estados Unidos que surgem os diversos exemplos de paisagens do medo de armas nucleares tão destoantes da materialidade do ocorrido em Hiroshima e Nagasaki. Com influências em diversos segmentos e contextos, desde literatos como Philip Dick (“Os sobreviventes”, 1962) e cineastas como Stanley Kubrik (Dr. Strangelove, 1962), até o auge do desenvolvimento narrativo de paisagens de medo das armas nucleares: a década de 1980.

Produções como a série distópica dirigida por George Miler (que ganhou um recente remake), Mad Max (1985), trazem consigo um forte teor de uma paisagem destruída, desértica, na qual a radiação e a destruição não permitiram a sobrevivência da maioria da população. Retorna-se para um estágio de selvageria, de busca de novas formas de controle social, uma vez que os valores humanos foram todos consumidos pela radiação. 


\section{CONSIDERAÇÕES FINAIS}

Essa paisagem distópica, essa paisagem do medo, é fruto de uma construção imagética de uma paisagem morta. Um topocidio é o que pode traduzir o medo das armas nucleares, quanto a sua percepção a paisagem. Pois se não há uma morte total da paisagem, há morte de elementos substancias da mesma: um campo que não produz, uma cidade que não pode ser habitada devido à radiação, pessoas que não conseguem viver na normalidade devido as doenças degenerativos que foram causadas pelo artefato entre outras questões.

A versão midiática do medo nuclear gerou um medo de viver em uma sociedade destruída, mas não só pelos seus prédios e destruições físicas. A principal mudança na paisagem é o papel que o ser humano executa nessas duas acepções. Na primeira é o papel de vítima, mas dentro de uma lógica de sobrevivência e organizacional que estamos habituados. $\mathrm{Na}$ outra há uma necessidade constante de rever a noção de humano, a noção biológica clássica (com a criação de monstros como Godzilla) e a própria forma de organização dos seres humanos é pautada por princípios diferenciados, pois as armas nucleares remodelariam não só a paisagem visível do mundo, mas sobretudo as paisagens escondidas nas entrelinhas das descrições daqueles que percebem o espaço vivido, como afirma Castrogiovani (2012).

\section{REFERÊNCIAS}

ANDERS, Günther. La Obsolescencia del Hombre: (Volumen I) Sobre el alma en la época de la segunda revolución industrial. Valência: Pré-textos, 2011.

CASTROGIOVANNI, Antonio Carlos (org). Ensino de Geografia: práticas e textualizações no cotidiano. Porto Alegre: Mediação, 2012.

CHAKARABARTY, Dipesh, Provincializing Europe: Postcolonial Thought and Historical Difference, Princeton, NJ: Princeton University Press, 2000.

JACOBS, Robert. Atomic Kids: Duck And Cover And Atomic Alert Teach American Children How To Survive Atomic Attack. Film \& History, n. 40, vol.1, 2010.

KEEGAN, John. Uma história da guerra. Tradução: Pedro Maia Soares. São Paulo: Companhia das Letras, 2006

KOONINGS, Kees; KRUIJT, Dirk. Introdutction: Violence and Fear in Latin America. In: KOONINGS, Kees; KRUIJT, Dirk (Org.). Societies of Fear: The Legacy of Civil War, Violence and Terror in Latin America. New York: St. Martin's Press, 1999.

NAKAZAWA, Keiji. Hadashi no Gen. Tokyo: Chuko Ronshinsha, 2010, Vol. 1-10 
SKOLL, Geoffrey. Social Theory of Fear: Terror, Torture, and Death in a Post-Capitalist World. New York: Palgrave Macmillan, 2010.

STEARNS. Peter. Fear and history. HISTOREIN, vol. 8, 2008.

TUAN, Yi-Fu. Espaço e Lugar. São Paulo: DIFEL, 1983.

Paisagens do medo. São Paulo: Ed. Unesp, 2005.

VIDAL-NAQUET, Pierre. Os Assassinos da Memória: um Eichmann de papel e outros ensaios sobre o revisionismo. Campinas: Papirus, 1987.

ZWIGENBERG, Ran. Hiroshima: The Origins of Global Memory Culture. Cambridge: Cambridge University Press, 2014. 